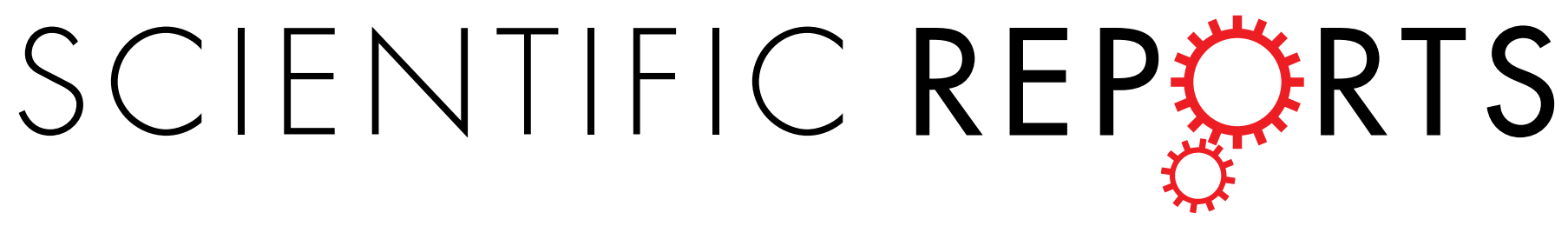

\title{
Corrigendum: DW-F5: A novel formulation against malignant melanoma from Wrightia tinctoria
}

Jayesh Antony, Minakshi Saikia, Vinod. V, Lekshmi. R. Nath, Mohana Rao Katiki, M.S.R. Murty, Anju Paul, Shabna A, Harsha Chandran, Sophia Margaret Joseph, Nishanth Kumar. S, Elizabeth Jayex Panakkal, Sriramya I. V, Sridivya I. V, Sophia Ran, Sankar S, Easwary Rajan \& Ruby John Anto

Scientific Reports 5:11107; doi: 10.1038/srep11107; published online 10 June 2015; updated on 03 August 2015

This Article contains an error in Fig. 8b; where the results from the purification of ${ }^{1} \mathrm{H}$ NMR of tryptanthrin were incorrectly provided. The correct Fig. 8b appears below as Fig. 1.

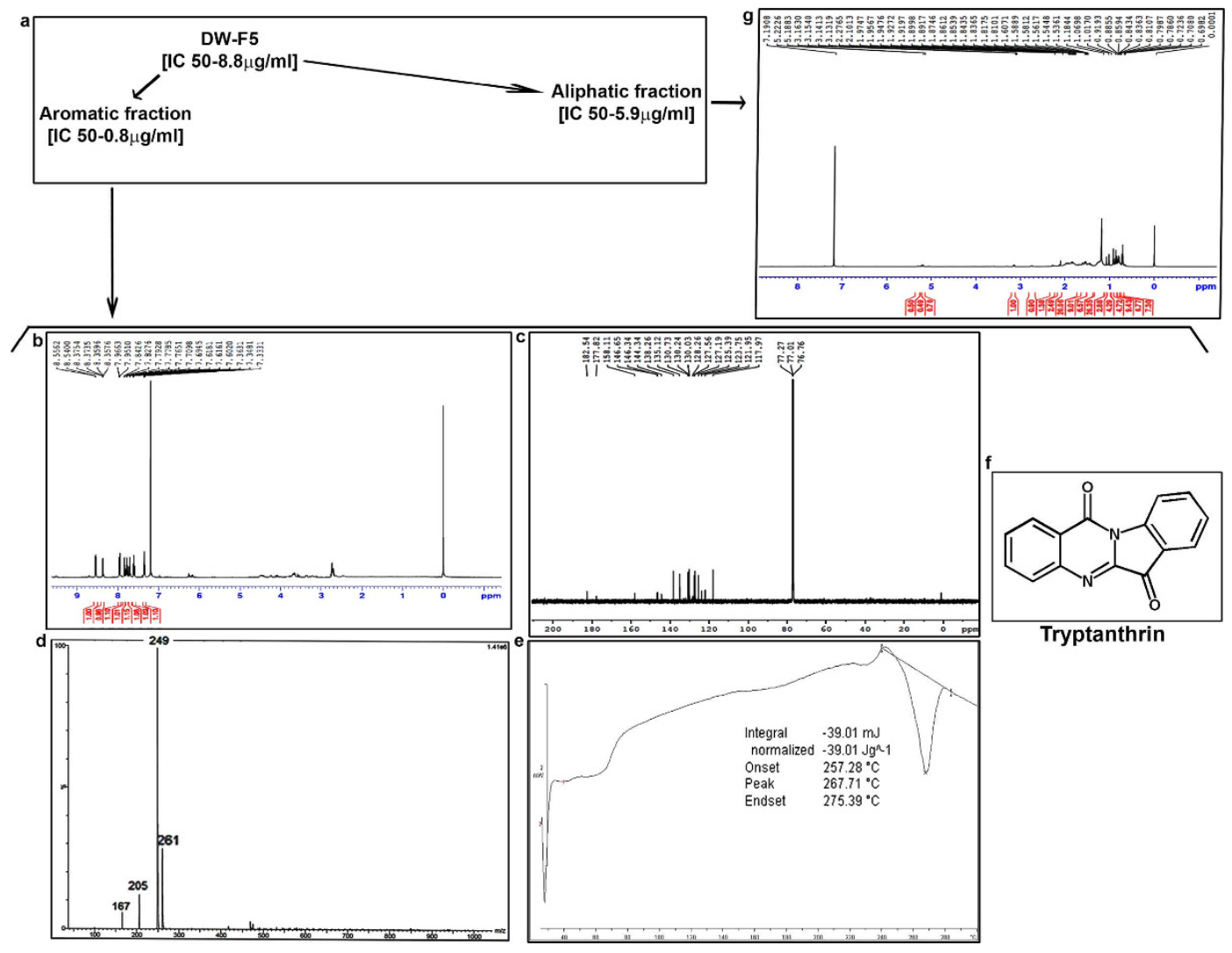

Figure 1. 